\title{
Researches On The E-commerce Model To Promote Regional Economic Development In Hebei Province
}

\author{
Zou Linyan \\ ShiJiaZhuang Vocational College of Finance and Economics \\ Shijiazhuang,Hebei 050061 China
}

\begin{abstract}
According to the environment of Hebei e-commerce's development,we can analyze current situation of e-commerce in Hebei,and we gained that development of e-commerce in Hebei should be taken by the mode of government support and enterprises as the mainstay market pulling synchronized,and we can promote e-commerce applications in various industries of various fields by improving the environment for development,improving protection mechanism,promoting technological innovation system,improving the level of ebusiness applications,adjusting regional structure and building industrial clusters.
\end{abstract}

Keywords- Hebei industry; E-commerce; Marketing model; Innovation

\section{THE NECESSITY OF THE E-COMMERCE DEVELOPMENT TO HEBEI ENTERPRISES}

Hebei Province is an important coastal province in northern China,and it is an important part of the Bohai economic rim. Beijing-Tianjin is inside of Hebei province,and the outside is the Bohai Sea.It has a long history and splendid culture, and it has a unique advantage in location, resources, transportation,communications, industry, and market.So it has a good environment for development.Since the reform and opening up,SMEs has been a rapid development in Hebei.To promoting the province's economic development it has played a positive role.It has an important role in stimulating economic growth,promoting employment, maintaining social stability, technological innovation and other aspects.Currently, the number of small and medium enterprises in Hebei Province has accounted for more than $95 \%$ of the total enterprises in the province.SMEs has become an important pillar of economic development in Hebei Province,and it made a great contribution to the economic growth in Hebei.But compared with the economically developed Guangdong, Jiangsu, Zhejiang and other provinces in the southeast coast,there is still a huge gap.The most important reason is that:Most e-commerce development of SMEs is relatively backward in Hebei,and it is difficult for them to face the Opportunities and challenges brought by China's accession to WTO effectively, and difficult to compete against the enterprises with large strength .So survival and development of SMEs will face a more severe test.In recent years, across the country,ecommerce transactions continue to grow rapidly.See Figure 1 and Figure 2.

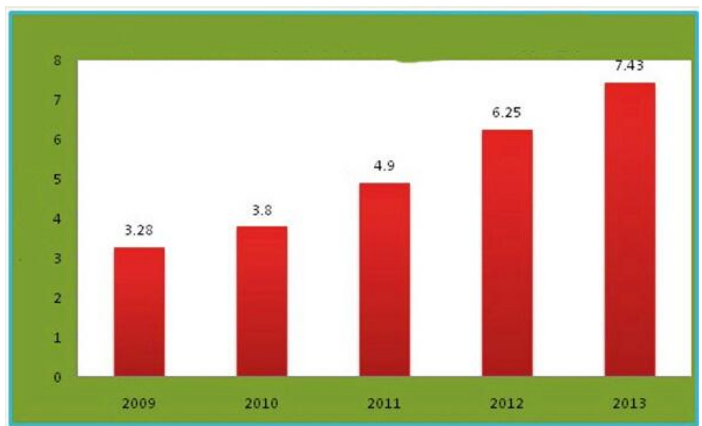

Figure 1 2009-2013 China B2B e-commerce market transaction size (unit: trillion yuan)

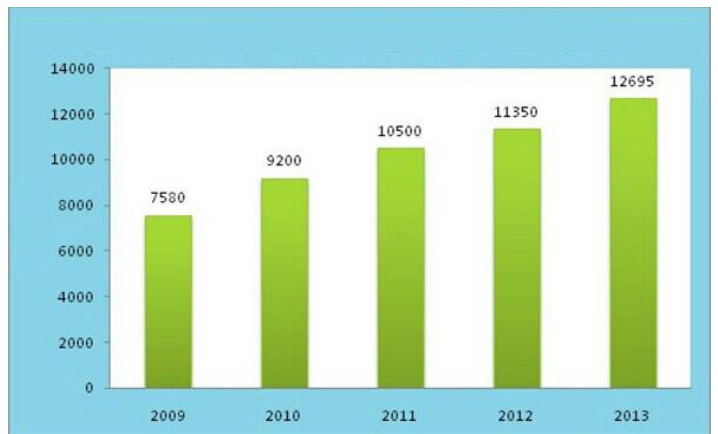

Figure 2 2009-2013 China B2B e-commerce market enterprise size (units: one) Source: China Electronic Commerce Research Center

From the above data, we can see that:In nationwide,both the amount of e-commerce market transactions or enterprise size have gained the rapid growth.It can be learned that ,ecommerce is the trend of the enterprises development.Focus on investment in e-commerce has become an inevitable trend in the development of enterprises in Hebei Province. 


\section{HEBEI'S E-COMMERCE DEVELOPMENT MODEL INNOVATION}

\section{A. The situation of Hebei e-commerce development}

1) Expansion of the market brought new demands for ecommerce development in Hebei.Global e-commerce has maintained rapid growth momentum,and this greatly improves our e-commerce market size, position and role.In 2012, Chinese e-commerce transactions exceeded 8 trillion yuan,and increased of $31.7 \%$. Internet retail sales exceeded 1.3 trillion yuan, and increased of $67.5 \%$.The annual industry revenue is 200 billion yuan.In 2012, the social networking sites, online shopping, online payment using of the Hebei Province were higher than the national average. We can make use of domestic and international environment to enhance market size, increase investment, and use the e-commerce development effectively.

2) IT development creates new conditions for the development of electronic commerce in Hebei.Information and communication technology, the next generation mobile communication technology, the next generation of the Internet, cloud computing are basis technical support to the e-business model innovation development .At the same time, it also accelerated the process of global competition and cooperation of e-commerce.The development of triple play, intelligent search and social networking and other new technologies has created better opportunities for the development of electronic commerce.Innovation and development of e-commerce will effectively use this opportunity.

3) Two of integration bring new space for e-commerce development in Hebei.In the process of gradually from transition of service-based to product-based, achieving services to diversity and differentiation.Resource allocation efficiency, operations management and overall innovation capacity of traditional industries in Hebei Province will be enhanced,which helps to change the operating thinking and operating mode and realize economic transformation and upgrading. Two of integration bring new space for ecommerce development in Hebei. Enterprise will be achieved value chain's integration and convergence inside , and promote the application of information technology and services in traditional businesses.

4) Regional differences brings new challenges to ecommerce development in Hebei. Beijing, Yangtze River Delta, Pearl River Delta and other economically developed areas are involved earlier in the field of electronic commerce, occupying the commanding heights of e-commerce and used advanced techniques for the local economy to make the economy develope towards a healthy and rapid track.Differences of e-commerce in mid-west are becoming increasingly severe.Sichuan, Henan and other places have introduced e-commerce development plan,and they defined the idea,targeting, priorities and safeguards of e-commerce development.Their development practices provide useful ideas for the development of electronic commerce in Hebei Province, and bring new challenges to seeking a breakthrough for E-commerce of Hebei Province and realizing the leaping development .

5) Policy guidance for the breakthrough in the development of e-commerce has brought new opportunities in Hebei.Following the National Development and Reform Commission "to further promote the healthy and rapid development of e-commerce related work" the State Council made great efforts to develop e-commerce, improve ecommerce transaction volume, and make Three-year average annual growth of information consumption scale achieve after"12 five" . This will be a good opportunity for continuous improvement of e-commerce services of Hebei Province.

\section{B. Hebei e-commerce development mode selection}

Combined with the status of e-commerce development in Hebei and Problems,to the choice of e-commerce development in Hebei model, we should take the model of government support and business-oriented market traction synchronized.The first is Government support.Starting with the construction of e-business and e-commerce demonstration project logistics system construction project,we can build e-commerce demonstration base,foster e-commerce business model, and in rural areas build business information services demonstration counties (districts).Construct key logistics park,actively introduce ecommerce logistics center construction project,strengthen regional logistics and distribution functions, and Significantly improve logistics support capabilities for the development of electronic commerce.Construct Logistics Public Information Platform. Encourage and guide the local logistics enterprise with core business capabilities and distribution ability to accelerate the improvement of information platform for building .Support the networking technology to develope ,promote and construct.Focus on the development of professional networking operating systems, database software, application software, and internet system integration .Second, enterprises as the mainstay of the market traction mode.Improve enterprise e-commerce application service levels, and construct various e-commerce platform including the production class e-commerce application platform,consumer e-commerce application platform, the service class e-commerce application platform, feature class e-commerce application platform.

\section{HEBEI REALIZATION PATH OF E-COMMERCE DEVELOPMENT MODEL INNOVATION}

In the current stage of development of electronic commerce in Hebei,according to the characteristics of ecommerce development in Hebei and government access areas, Hebei e-commerce development should choose enterprises, government support for the free market adjustment mode.To achieve the success of this model select,government must play a leading role in many aspects related to electronic commerce to adapt to the status of ecommerce development in Hebei.That is, do the following aspects to ensure leapfrog development of e-commerce. 


\section{A. Improve the development environment, and improve security mechanism}

Actively develop e-commerce logistics and distribution.A certain degree of improvement and perfection should be done in the public distribution center logistics, distribution transit stations, distribution networks and other community infrastructure to built logistics center to protect the distribution.Constantly improve the professional standards of modern logistics enterprise services.Encourage regional and industrial logistics information platform, to support e-business and logistics enterprises database's docking.Regulate the development of electronic payment business services.Insurance, funds, universities, cross-border and other electronic payment services in emerging market segments continue evolving, and Electronic payment trend to diversify.Meet the needs of E-commerce activities' diverse and personalized payment,and promote the development of e-commerce and electronic payment integration.Actively promote the city "One-Card" project. Realize to support rapid and sustainable development of the area of ecommerce from the payment of traffic, public utilities fee and other basic services,to health care, food, trade, tourism and other daily life areas .

\section{B. Promote technological innovation system, and improve e-commerce application}

Hebei will realize the innovation of e-commerce model, should promote technological innovation system and improve the level of e-business applications.It should let the new information and communication technologies as basis by effectively develop cloud computing,big data, networking and next-generation mobile communications technology to expand and improve e-commerce technology innovation.Promote large-scale trade and business enterprises should be done through e-commerce to improve circulation efficiency and expand distribution channels and market space.Collaborate on e-commerce supply chain,and realize real-time communication among enterprises,enterprises and customers.Expand and support development of information systems.Encourage the development of internal e-commerce platform and improve their level of application.Start special support program.Provide multilevel e-commerce training programs and special support fund.Support large-scale enterprise ecommerce applications in depth.Promote SMEs to use Ecommerce widely to enhance the advantages industry's overall application level of e-commerce.

\section{Adjust regional structure and create industrial clusters}

Promote the development of e-commerce.We should adjust regional structure and build e-commerce demonstration base.Develope e-commerce, specialty agricultural products from modern agricultural production organization to the chain supermarket.Promote agriculturerelated e-commerce platform.Encourage equipment manufacturing, automobile manufacturing, aerospace, energy, chemical and other advantage industry e-commerce development model innovation.Grow and develop a number of professional e-commerce trading platform. Promote the service delivery areas transformation of tourism, culture,commerce,education,etc.Promote the industry development model of network and entity.Relying on national e-commerce demonstration base - - Xi'an Hightech Zone and other existing industrial parks resources,strengthen the construction plan of the gathering area of e-commerce further, improve the comprehensive service system, create a number of e-commerce business base and industrial demonstration zone and promote industrial development of regional e-commerce.

\section{Promote e-business applications in various industries and fields further}

With the services expanding, e-commerce application model becomes increasingly diversified in Hebei. Cultural industries, digital publishing, community services, tourism, education and other fields have adopted e-commerce means to enhance the level of service.The province's mainstream traditional media gradually realized the digital service.Ecommerce community gradually being implemented and real estate, ticketing and other intermediary services have implemented online booking.The major tourist attractions relying on the Internet to carry out travel ticketing, catering ,accommodation and other online marketing. Online direct marketing, e-retail,online booking, online financial,lifestyle information services provide consumers to consumer convenience, lifestyle information, interactive space with e-commerce services. We must further promote ebusiness applications in various industries, fields, to strengthen production ,study, and research cooperation of ecommerce.

\section{ACKNOWLEDGEMENT}

This article is research result of "2014 colleges and universities scientific research projects in Hebei Province",item Code: SZ141220.

\section{REFERENCES}

[1]Tan Xiaolin,Xie Wei,Li Peixin.Classification application and innovation of e-business models[J].Technical and economic,2010,10:6 -11 to +18 .

[2]Shen Jingtao.E-commerce and Business Model Innovation[J].Business Research,2010,16:98-99.

[3]Ping Aihong. In e-commerce environment ,companies procurement model innovation $[\mathrm{J}]$. Wuhan University of Science and Technology, 2002,03:103-106.

[4]Fang Zi, Wang Kanliang. Analysis and methods innovation of e-business models $[\mathrm{J}]$. Xi'an Jiaotong University (Social Science Edition), 2002,02:65-69.

[5]Shen Qing. Zhejiang E-Commerce Innovation Research of Business Model——such as Alibaba B2B companies[A].Zhejiang rise and crisis response $[\mathrm{C}]:, 2010: 8$.

[6]Zhang Hong,Wang Zhe. Shaanxi model innovation and realization path of e-commerce development [J]. Contemporary Economic,2014,07:8687. 